\title{
A CONTABILIDADE AMBIENTAL EM EMPRESAS CERTIFICADAS PELAS NORMAS ISO 14001 NA REGIÃO METROPOLITANA DE BELO HORIZONTE-MG ${ }^{1}$
}

\author{
Walmer Faroni², Suely de Fátima Ramos Silveira², Elizete Aparecida de Magalhães e Elenice Maria \\ de Magalhães ${ }^{4}$
}

\begin{abstract}
RESUMO - As empresas que adotaram um Sistema de Gestão Ambiental necessitam cumprir as normas ISO 14001 e ter o controle dos recursos para tomar decisões. A contabilidade exerce importante papel no fornecimento de informações aos gestores, possibilitando-lhes maior eficiência na gestão do meio ambiente. Assim, este estudo teve como propósito analisar a utilização do conceito e instrumentos da Contabilidade Ambiental nas empresas certificadas pela ISO 14001. Os dados foram obtidos por meio da aplicação de questionários semiestruturados aos contadores e gestores ambientais de 10 empresas da região metropolitana de Belo Horizonte. Constatou-se que as empresas estudadas não utilizam os instrumentos de Contabilidade Ambiental para tomar as decisões relacionadas ao meio ambiente e, sim, a contabilidade tradicional. Quanto à ocorrência de mudanças na contabilidade após a obtenção da certificação ambiental, verificou-se que não houve mudança nas demonstrações contábeis tradicionais. Algumas empresas apenas incluíram contas específicas em seus planos de contas, destinadas à contabilização de eventos ambientais. Destaca-se, ainda, a falta de conhecimento, por parte de alguns contadores e gestores entrevistados, dos benefícios que a utilização da Contabilidade Ambiental pode trazer para os negócios da empresa.
\end{abstract}

Palavras-chave: Contabilidade ambiental, Certificação ambiental - ISO 14001 e Gestão ambiental.

\section{ENVIRONMENTAL ACCOUNTING IN COMPANIES CERTIFIED BY ISO 14001 IN THE METROPOLITAN REGION OF BELO HORIZONTE (MG)}

\begin{abstract}
Companies which adopted the Environmental Management System need to comply with ISO 14001 and to control resource allocation in order to make decisions. The accounting exerts an important role on supplying information to managers on helping managing the environment. This study aims to analyze the importance of the Environmental Accounting concepts and tools for companies certified by ISO 14001. Data were collected through semi-structured questionnaires with accountants and environmental managers from a sample of 10 companies from the metropolitan region of Belo Horizonte. It has been demonstrated that these companies do not employ Environmental Accounting tools for making the decisions related to their environments; instead they use traditional Accounting. As for the occurrence of changes in the Accounting process after awarded with the environmental certification, the investigation demonstrated that the traditional accounting reports did not changed. Some companies just included specific items in their plans in order to encompass the environmental events. The investigation also detected a lack of knowledge - in the discourse of some respondents - about the benefits of employing the Environmental Accounting in the managerial process of the companies.
\end{abstract}

Keywords: Environmental accounting, Environmental certification - ISO 14001 and Environmental management.

\footnotetext{
${ }^{1}$ Recebido em 12.07.2006 e aceito para publicação em 25.08.2010.

${ }^{2}$ Universidade Federal de Viçosa, UFV, Brasil. E-mail: <sramos@ufv.br>.

${ }^{3}$ Universidade Federal dos Vales do Jequitinhonha e Mucuri, UFVJM, Brasil.

${ }^{4}$ Universidade Presidente Antônio Carlos, UNIPAC, Brasil..
} 


\section{INTRODUÇÃO}

A questão ambiental tem sido objeto de estudo pelas diversas áreas do conhecimento, como administração, contabilidade, economia e engenharias em geral. A internacionalização dos padrões de qualidade ambiental descritos na série ISO 14000, a globalização dos negócios, a crescente conscientização dos consumidores atuais e a disseminação da educação ambiental nas escolas são fatores que permitem prever que as exigências futuras dos consumidores em relação à preservação do meio ambiente e à qualidade de vida deverão se intensificar.

A preocupação com os riscos e danos ao meio ambiente foi além dos limites dos grupos ambientalistas, e disseminou-se entre a população mundial, atingindo as empresas e, também, a contabilidade. Os ambientalistas ressaltaram o importante papel da adoção de medidas de proteção e gestão ambiental, buscando a adesão de instrumentos e metodologias que demonstrem que a preservação do meio ambiente pode ser menos dispendiosa para as empresas do que os impactos ambientais de suas atividades.

Nesse contexto, muitas empresas estão adotando voluntariamente a ISO 14000, que compreende um conjunto de normas ambientais internacionais, não obrigatórias, que possibilitam a obtenção da Certificação Ambiental. Porém, essa certificação só é obtida após a implantação de um Sistema de Gerenciamento Ambiental que estabelece requisitos para as empresas gerenciarem seus produtos, serviços e processos, de modo que não afetem o meio ambiente.

As empresas que possuem um Sistema de Gerenciamento Ambiental necessitam cumprir as normas da ISO 14001, ter controle de custos e recursos para tomar as decisões de gestão ambiental. Assim, surge um novo ramo da contabilidade - a Contabilidade Ambiental, que possui a função de fornecer informações para auxiliar os administradores no gerenciamento empresarial do meio ambiente.

Como Contabilidade Ambiental é uma área nova, a literatura contábil-acadêmica sobre o assunto é relativamente recente. Em razão da preocupação da sociedade com as questões ambientais e sua evolução no âmbito empresarial, é fundamental que sejam realizados estudos mais detalhados sobre o tema para que se possa identificar o estágio atual desse novo ramo do conhecimento, além de apresentar contribuições para a sua difusão.
Este estudo teve como propósito analisar a utilização do conceito e dos instrumentos da Contabilidade Ambiental em empresas certificadas pela ISO 14001, de Belo Horizonte, MG.

\section{REFERENCIAL TEÓRICO}

\subsection{Contabilidade ambiental}

A contabilidade como ciência social, influenciada por mudanças sociais, políticas e econômicas, tem seus desafios. Surgem, a cada dia, novas necessidades, e entre elas está a demanda por informações de caráter financeiro-ambiental das empresas. Para atender a essa nova função da contabilidade, surge em 1970 a Contabilidade Ambiental, quando as empresas passaram a dar maior atenção aos problemas ambientais.

Bergamini Júnior (2000) definiu Contabilidade Ambiental como o estudo do patrimônio ambiental (bens, direitos e obrigações ambientais) das empresas. Tem como finalidade fornecer aos seus usuários, internos e externos, informações sobre os eventos ambientais que provocam modificações na situação patrimonial, bem como realizar sua identificação e mensuração.

Segundo Cardoso (2006), a Contabilidade Ambiental é um modelo que permite subsidiar e prover o desenvolvimento sustentável, uma vez que há neste novo ramo da contabilidade a mensuração de dados como forma de prestar conta à sociedade e aos acionistas.

A Contabilidade Ambiental não é uma nova contabilidade, mas um conjunto de informações que expõe, em termos econômicos, as ações de uma organização que causam modificações em seu patrimônio. Constitui-se, portanto, em especialização da Contabilidade. De acordo com Ferreira (2003), a expansão da contabilidade para a área do meio ambiente é consequência da necessidade de oferecer informações adequadas às características de uma gestão ambiental.

O Brasil apresenta avanços modestos na identificação e mensuração dos eventos ambientais nas demonstrações contábeis das empresas. O Conselho Federal de Contabilidade (CFC), com o intuito de auxiliar as empresas brasileiras a contabilizarem suas ações ambientais, desenvolveu a norma NBC T 15 para registro e apuração de saldos relativos ao meio ambiente em seus balanços. A referida norma foi aprovada pela Resolução CFC n. ${ }^{\circ}$ 1.003/04 e estabelece procedimentos para evidenciar as informações de naturezas social e ambiental (BRASIL, 2004). 
No que se refere ao âmbito internacional, Cosenza e Kroetz (2006) afirmaram que legalmente não há regras e normas contábeis quanto à forma e critérios de mensuração e evidenciação das informações de natureza ambiental. As poucas propostas sobre a normalização se preocupam especificamente com a evidenciação de informações ambientais, e seu teor concentra em dados considerados importantes, mas não mostra a maneira de integrá-los ao sistema de informação contábil.

A Contabilidade Financeira Ambiental destinase ao registro dos eventos relacionados ao meio ambiente, propondo-se a divulgar o relato ambiental de forma destacada nas Demonstrações Contábeis. Portanto, sua implementação depende de uma política contábil definida, que considere a separação dos itens relativos aos impactos ambientais das atividades empresariais no meio ambiente.

Ainda não há consenso sobre o que deve constar nos relatórios de Contabilidade Ambiental. Acreditase que devem ser incluídas, além das exigências legais, informações “voluntárias” sobre as questões ambientais. Espera-se que os aspectos financeiros da Contabilidade Ambiental se tornem mais claros e precisos com o passar do tempo (NOSSA, 2002).

A aplicação da Contabilidade Ambiental nas empresas pode parecer simples, mas, na prática, são encontradas algumas dificuldades que, de certa forma, impossibilitam o seu desenvolvimento. A principal delas consiste na separação das informações de natureza ambiental das informações globais da empresa, assim como sua adequada classificação contábil. Em resumo, é inegável a importância do desenvolvimento e difusão da Contabilidade Ambiental como uma nova especialidade da ciência contábil, voltada para instrumentalizar, de forma adequada, o relato do desempenho ambiental.

\subsubsection{Ativo ambiental}

No entendimento de Bergamini Júnior (2000, p. 20):

O ativo ambiental é um recurso controlado por uma empresa que surge de eventos passados e de onde são esperados futuros fluxos de benefícios econômicos diretos ou indiretos para a empresa, através de aumento da capacidade, aumento da segurança ou eficiência de outros ativos próprios da empresa, redução ou prevenção de possível contaminação ambiental resultante de futuras operações e conservação do meio ambiente.
Essa assertiva é também aceita pela United Nations Conference on Trade and Development - Unctad (1998), ao afirmar que ativos ambientais são gastos capitalizados e amortizados nos períodos presente e futuro, que atendem aos critérios de reconhecimento como um ativo. Desse modo, o ativo é recurso controlado por uma empresa como resultado de eventos passados e dos quais se esperam benefícios econômicos futuros.

Portanto, o ativo ambiental consiste nos bens e direitos destinados ou provenientes da atividade de gerenciamento ambiental, ou seja, são os bens da empresa que visam à preservação, proteção e recuperação ambiental e deveriam vir à parte nas demonstrações contábeis da empresa, de modo a tornar suas ações mais transparentes e também possibilitar ao usuário melhor avaliação das ações ambientais da organização.

\subsubsection{Passivo ambiental}

O passivo ambiental consiste em toda e qualquer obrigação em curto e longo prazos, contraída voluntária ou involuntariamente, destinada a promover investimento em ações de controle, preservação e recuperação do meio ambiente, originando, como contrapartida, um ativo ou custo ambiental.

Passivo Ambiental refere-se a benefícios econômicos que serão sacrificados em função de obrigação contraída perante terceiros para a preservação e proteção ao meio ambiente. Tem origem em gastos relativos ao meio ambiente, que podem se constituir em despesas do período atual ou anteriores, e aquisição de bens permanentes (MARTINS e DE LUCA, 1994, p. 27).

Os passivos ambientais, conforme Ribeiro e Gratão (2000), ficaram conhecidos pela sua conotação mais negativa, ou seja, as empresas que os têm agrediram significativamente o meio ambiente e, dessa forma, têm que pagar um montante a título de indenização a terceiros, de multas e para a recuperação de áreas danificadas.

Deve-se salientar, entretanto, que os passivos ambientais não possuem origem apenas em fatos de conotação negativa. Esses podem ser provenientes de atitudes ambientalmente responsáveis como aquelas decorrentes da manutenção de sistema de gerenciamento ambiental. Tais sistemas necessitam de pessoas para a sua operacionalização, bem como a aquisição de insumos, máquinas, equipamentos e instalações para 
funcionamento, o que, muitas vezes, será feito na forma de financiamento direto dos fornecedores ou por meio de instituição de crédito.

\subsubsection{Custos ambientais}

Os custos ambientais são gastos em aplicação direta no sistema de gerenciamento ambiental do processo produtivo e nas atividades ecológicas da empresa. Na visão de Ribeiro (1998), os custos ambientais são representados pelo somatório de todos os custos dos recursos utilizados pelas empresas em suas atividades, com o intuito de controlar, preservar e recuperar o meio ambiente.

Para a United States Environmental Protection Agency - EPA (1995), os custos que obedecem às leis ambientais são definidos claramente como custos ambientais. Alguns custos como correção ambiental, equipamento para controle de poluição são inquestionavelmente custos ambientais. Outros custos incorridos para proteção ambiental são classificados claramente como custos ambientais até mesmo se eles não estão explicitamente definidos em regulamentos. Porém, há outros custos que são difíceis de distinguir se são ambientais, como o de equipamento de produção, uma vez que é considerado tecnologia “limpa”.

Os custos ambientais estão relacionados a multas, indenizações a prejuízos causados a terceiros, recuperação de áreas degradadas pela empresa e impostos sobre produtos poluidores, bem como gastos com tratamento de saúde de funcionários. A identificação desses custos ainda constitui-se em uma difícil tarefa, pois não há uma forma adequada, padronizada, de mensurar muitos de seus componentes, considerados como intangíveis.

\subsubsection{Receita ambiental}

A receita refere-se ao acréscimo de benefícios econômicos durante um exercício financeiro na forma de entrada de recursos ou decréscimo de exigibilidade, que resulta em aumento do patrimônio líquido da empresa.

De acordo com Soares e Andrade (2000), a implantação do sistema de gestão ambiental não visa apenas gerar receita para a empresa, mas também desenvolver uma política responsável em relação aos problemas ambientais, o que não impede que a empresa tire algum proveito econômico desse processo. Como exemplos de receitas ambientais, citam-se a prestação de serviços especializados em gestão ambiental; a venda de produtos elaborados a partir de sobras de insumos do processo produtivo; e a participação no faturamento total da empresa que se reconhece como resultante de sua atuação responsável pelo meio ambiente.

Na Tabela 1, tem-se uma representação ilustrativa dos benefícios (receitas) e custos ambientais. Demonstra-se que é mais interessante para uma empresa investir em prevenção ambiental, visto que o custo do impacto ambiental causado por degradação do meio ambiente pode ser maior que o custo do impacto quando a empresa adota medidas preventivas. Na ilustração, a empresa quando investe em prevenção do meio ambiente reduzirá o seu custo em $60 \%$, gastando para isso R\$100.000,00. Assim, a empresa terá um ganho de $\mathrm{R} \$ 200.000,00$, isto é, R\$300.000,00, de economia nos custos, menos R $\$ 100.000,00$ investidos para obter esse resultado.

\subsection{A contabilidade como sistema de informação para o gestor ambiental}

A Contabilidade pode contribuir com a sociedade, buscando soluções para os problemas sociais, pois essa ciência, como meio de fornecer informações, deve responder a esse novo desafio, satisfazendo os usuários interessados na atuação das empresas sobre o meio ambiente, devendo, ainda, contribuir para a tomada de decisão. Além disso, deve incorporar questões ecológicas e ambientais nos seus registros, nas contabilizações e nas divulgações aos usuários da informação contábil.

Na concepção de Kraemer (2000, p. 20):

A contabilidade vista como um sistema de informação da situação e da evolução patrimonial, econômica e financeira da empresa, deve incluir em seus relatórios todos os dados relacionados ao meio ambiente, facilitando o acesso a mais esta informação ao seu grande número de usuários, auxiliando-os no processo de tomada de decisão.

As informações contábeis devem estar disponíveis no momento necessário e organizadas de maneira a atender ao processo decisório dos gestores ambientais. Dessa forma, o papel da contabilidade é o de prover informações que auxiliem os gestores na tomada de decisões referentes ao meio ambiente, de modo a inibir resultados que possam afetá-lo. 
Tabela 1 - Demonstração dos custos e receitas ambientais. Table 1-Demonstration of the costs and environmental incomes.

\begin{tabular}{|c|c|c|c|}
\hline \multicolumn{2}{|c|}{ Impacto ambiental } & \multicolumn{2}{|c|}{ Prevenção ambiental } \\
\hline Custo do impacto (A) & $\mathrm{R} \$ 500.000,00$ & Investimento (Prevenção) & $\mathrm{R} \$ 100.000,00$ \\
\hline Recuperação & $\mathrm{R} \$ 300.000,00$ & Custo do Impacto (B) & $\mathrm{R} \$ 200.000,00$ \\
\hline Indenização & $\mathrm{R} \$ 150.000,00$ & & \\
\hline Multa & & $\mathrm{R} \$ 50.000,00$ & \\
\hline Economia de custos (A-B) & & & $\mathrm{R} \$ 300.000,00$ \\
\hline
\end{tabular}

Fonte: Elaborado com base em FERREIRA, 2003.

Source: Based on FERREIRA, 2003.

Sendo a contabilidade importante instrumento de identificação, registro, análise e interpretação das operações empresariais aos usuários externos e internos, ela se configura como o melhor mecanismo de gestão disponível ao empresariado, cujos resultados apurados podem ser visíveis à sociedade mediante a apresentação de Demonstrações Contábeis.

\subsection{Gestão ambiental}

Segundo Ferreira (1998), o processo de gestão ambiental considera todas aquelas variáveis de um processo de gestão, como o estabelecimento de políticas, planejamento, um plano de ação, apropriação de recursos, determinação de responsabilidade, decisão, controle, visando, especificamente, ao desenvolvimento sustentável.

A gestão ambiental constitui um conjunto de medidas que visam ter controle sobre o impacto ambiental de uma organização. É a forma pela qual a organização se mobiliza, interna e externamente, para alcançar a qualidade ambiental desejada. Segundo Oliveira Filho (2002), a inclusão de questões ambientais na empresa passam a ter valor nas decisões, nas políticas, nos planos de ação e permite divulgar ao mercado o comprometimento da organização com o meio ambiente.

A partir do entendimento da contabilidade como instrumento relevante para a gestão empresarial e para o registro e informação de dados ambientais resultantes do processo produtivo das empresas, torna-se evidente que sistemas de gestão ambiental devem estar integrados às análises contábeis. Portanto, um Sistema de Gestão Ambiental pode ser entendido como um conjunto de normas para administrar e gerir uma empresa, de modo a obter um relacionamento eficaz com o meio ambiente.

\subsection{Certificação ambiental - ISO 14000 e 14001}

A International Organization for Standardization (ISO) é uma federação internacional civil de organizações de normalização, sem fins lucrativos. As normas produzidas pela ISO têm caráter voluntário, não existindo mecanismos legais que obriguem sua adoção por qualquer tipo de empresa. A Associação Brasileira de Normas Técnicas (ABNT) é a representante oficial do Brasil na ISO.

De acordo com Nardelli e Griffith (2000), a ISO 14000 constitui uma série de normas editadas pela referida organização, com a finalidade de padronizar a implantação voluntária de Sistema de Gerenciamento Ambiental (SGA) nos diversos ramos da atividade humana. As normas contidas na Série ISO 14000 fornecem, à administração, os instrumentos necessários para o gerenciamento dos potenciais impactos ambientais de um empreendimento, no que se refere às atividades, aos produtos e aos serviços.

As empresas que procurarem sua certificação ou registro o farão de acordo com a ISO 14001, que é a norma de especificação do modelo de Sistema de Gerenciamento Ambiental. Essa norma estabelece requisitos para as empresas gerenciarem seus produtos, serviços e processos, de maneira que não afetem prejudicialmente o meio ambiente e a comunidade.

Epelbaum (2004) buscou identificar os principais benefícios da implementação do SGA nas empresas. Percebeu que os benefícios atingidos são: atendimento de critérios de clientes e investidores; diminuição dos custos pela redução da poluição, conservação de materiais e energia; aumento da conscientização dos funcionários; e melhoria do clima organizacional e da imagem da empresa.

Revista Árvore, Viçosa-MG, v.34, n.6, p.1119-1128, 2010 
Segundo Viana et al. (2003), a certificação ambiental consiste em uma ferramenta fundamental para proteção do meio ambiente. Acrescenta ainda que a certificação, do ponto de vista ambiental, tem por objetivo atestar o comportamento dos empresários. Isso pode ser feito com base em determinadas normas e regras estabelecidas por instituições normatizadoras ou por grupos constituídos por essas instituições.

Os sistemas de gestão descrevem o modo pelo qual o trabalho de uma organização deve ser conduzido. Eles são apresentados de forma clara, a fim de assegurar que os métodos e as práticas possam ser verificados segundo os objetivos. O sistema de gestão permite que sistemas de diferentes organizações possam ser comparados, possibilitando aos consumidores e aos governos o controle das ações dos seus fornecedores.

\section{PROCEDIMENTOS METODOLÓGICOS}

A pesquisa classificou-se como exploratória, que, segundo Vergara (2005), é um tipo de pesquisa que pretende atingir uma área na qual há pouco conhecimento acumulado, permitindo esclarecer os principais conceitos acerca do fenômeno que deseja investigar. Este estudo caracterizou-se, ainda, como descritivo. Para a referida autora, a pesquisa descritiva é aquela que expõe características de determinado fenômeno, estabelecendo correlações entre variáveis.

A relação das empresas de Minas Gerais certificadas pela Norma ISO 14001 foi obtida no Instituto Nacional de Metrologia (Inmetro); em 4 de abril de 2004, eram 36 empresas. A amostra foi composta de 10 empresas da região metropolitana de Belo Horizonte, que demonstraram interesse em participar da pesquisa, o que facilitou as visitas para as entrevistas.

Das empresas pesquisadas, a metade possuía mais de quatro anos de Certificação Ambiental no momento da realização da pesquisa (2004). São empresas de médio e grande portes, pertencentes a vários setores, como petrolífero, automobilístico, elétrico, siderúrgico, químico e de reciclagem.

A partir da literatura consultada, elaboraram-se dois questionários semiestruturados. Para a validação dos questionários foi feito um pré-teste em uma empresa de Belo Horizonte. Os questionários abordaram questões sobre Contabilidade Ambiental, como: impacto da implantação da ISO 14001 e a operacionalização do SGA sobre os custos da empresa; conhecimento da
Contabilidade Ambiental, bem como sua finalidade; prática da Contabilidade Ambiental nas empresas; importância atribuída à Contabilidade Ambiental e dificuldades encontradas.

Os sujeitos sociais da pesquisa foram os gestores ambientais e contadores que são responsáveis, respectivamente, pelos setores de SGA e de contabilidade das empresas. A maioria dos entrevistados foi do sexo masculino, possuía mais de 40 anos, e o nível de escolaridade tanto dos gestores quanto dos contadores concentrou-se em superior completo.

Os questionários foram aplicados na forma de entrevista pessoal, aos gestores ambientais e aos contadores. Assim, em cada empresa foram entrevistados um gestor e um contador, perfazendo um total de 20 entrevistados. O questionário possuía questões para as quais existia a possibilidade de mais de uma resposta, portanto o total de respostas ultrapassa o número de respondentes. As análises das informações obtidas dos contadores e gestores ambientais foram realizadas separadamente, de acordo com o conteúdo das entrevistas. Em função do número reduzido de empresas que demonstraram interesse em colaborar com a pesquisa, não foi possível fazer uma análise estatística detalhada, que permitisse validar os resultados dos questionários. Assim, os dados foram analisados com técnicas do programa Excel for Windows, como a análise de frequência e o cruzamento de dados.

\section{RESULTADO E DISCUSSÃO}

\subsection{Contabilidade ambiental sob a ótica dos contadores}

Das entrevistas com contadores das empresas, identificou-se, segundo declarações, que em quatro delas ocorreram mudanças na Contabilidade após a obtenção da Certificação Ambiental. Observou-se que, dessas, somente uma empresa modificou seu plano de contas, criando contas específicas, destinadas à contabilização dos custos ambientais. Portanto, verificase contradição nas respostas dos outros três entrevistados, pois argumentaram que a mudança ocorrida na contabilidade com a certificação foi a criação de contas específicas, mas, na realidade, isso não foi confirmado ao relatarem que não criaram novas contas em seus planos de contas. Verificou-se, pois, compreensão equivocada por parte desses contadores sobre a contabilidade ambiental. 
Das seis empresas que não realizaram mudança na contabilidade após a certificação, duas possuíam contas específicas para a contabilização dos ativos, passivos e custos ambientais e quatro não. Diante do exposto, verificou-se que a contabilização das ações ambientais executadas pela empresa ainda não se apresenta de forma estruturada nas empresas pesquisadas.

Quanto aos instrumentos utilizados para demonstrar as informações de natureza ambiental, verificou-se que seis empresas utilizavam o Relatório Administrativo, duas o Balanço Patrimonial (BP) e a Demonstração de Resultado de Exercício (DRE) e três o Balanço Social. Essas informações, entretanto, são evidenciadas não de forma separada, mas, sim, em conjunto com as demais informações contábeis da organização.

Das três empresas que elaboraram o Balanço Social, apenas uma fez o Balanço Social/Ambiental, cujo objetivo foi demonstrar as ações sociais e ambientais realizadas por ela. Deve-se ressaltar que o referido documento não consistiu em um balanço contábil/ambiental, pois não possuía valores numéricos. Os investimentos relativos ao meio ambiente estão inseridos na contabilidade tradicional.

Perguntados sobre o impacto da implantação da ISO 14001 nos custos da empresa, sete entrevistados argumentaram que os custos com a certificação aumentaram os custos totais da empresa. Esses custos são referentes a treinamento de pessoal, objetivando a conscientização sobre a importância da certificação para a organização. Os demais entrevistados afirmaram que a implantação da ISO não representou impacto sobre os custos, pois os valores dos custos de implantação comparados aos custos totais são irrelevantes, ou seja, os benefícios da certificação são maiores que o seu custo, uma vez que evita multas ambientais, reclamações da sociedade etc.

Também, constatou-se que a maioria dos contadores das empresas estudadas já tinha tomado conhecimento da contabilidade ambiental, e que as principais fontes de informações foram revistas e jornais, citados sete vezes, seguidos de seminários e congressos (6) e artigos (4). Como a contabilidade ambiental é especialização da contabilidade tradicional, não se tratando, portanto, de nova contabilidade, esperava-se que todos os contadores tivessem pelo menos um mínimo de conhecimento dela (Figura 1).
Fonte: Dados da pesquisa. Source: Research data.

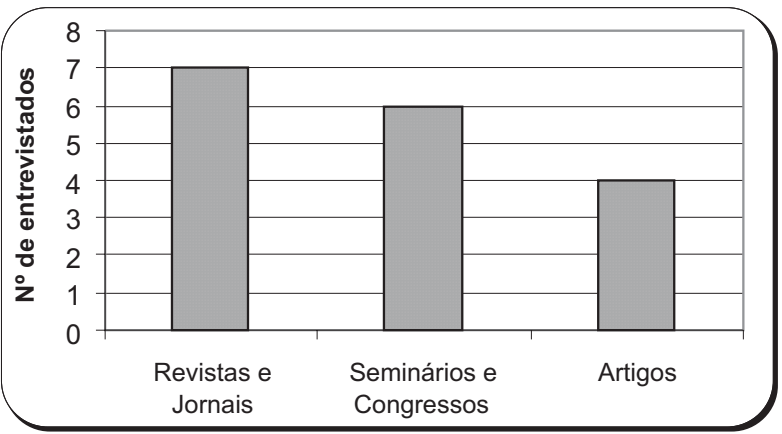

Figura 1 - Fontes de informações dos contadores sobre a Contabilidade Ambiental.

Figure 1 - Information sources of the accountants about Environmental Accounting.

Com o objetivo de verificar a disseminação e o desenvolvimento da Contabilidade Ambiental nas empresas certificadas pela Norma ISO 14001, os entrevistados foram questionados a respeito da existência de alguma prática desse novo ramo da contabilidade, a exemplo da realização de demonstrações contábeis, como o Balanço Patrimonial e a Demonstração de Resultado de Exercício, evidenciando como as questões ambientais estão sendo tratadas nessas empresas. Porém, observou-se em todas as empresas a inexistência da referida contabilidade.

Durante a entrevista, todos os contadores declararam que os custos referentes ao meio ambiente são apropriados ao centro de custo como os demais custos da empresa. Em duas empresas, foi identificado um centro de custo representativo do gerenciamento das atividades do meio ambiente. Diante do exposto, verificou-se que somente essas últimas possuíam controle dos custos referentes ao meio ambiente.

Os motivos da não existência da contabilidade ambiental, de acordo com os contadores entrevistados, devem-se, principalmente, à falta de conhecimento aprofundado sobre o assunto, à inexistência de exigência legal e à dificuldade de implantá-la. Essas dificuldades se devem, em muitos casos, à falta de mão de obra especializada para realizar a contabilidade ambiental. Através de comentários de alguns entrevistados, percebeu-se que, para aplicá-la, é necessário que a empresa tenha um profissional com conhecimentos das normas e de procedimentos contábeis e também de gestão ambiental, o que, segundo afirmaram, ainda requer melhor preparação dos profissionais. 
Como as empresas não realizam a contabilidade ambiental, tentou-se averiguar a forma como os contadores tratavam os resultados das ações e questões ambientais. A maioria declarou que não havia separação e que registravam esses itens juntamente com as demais ações da empresa, ou seja, utilizavam o mesmo procedimento de qualquer outra ação da organização. As duas empresas que adaptaram instrumentos contábeis referem-se àquelas que possuem centro de custo ambiental. Para isso, foi necessário realizar uma modificação em seus planos de contas. Os entrevistados consideravam o centro de custo ambiental como um relatório específico, destinado ao controle dos custos internos e externos referentes ao meio ambiente.

Foi possível verificar que em apenas quatro empresas pesquisadas já se discutiu a possibilidade de iniciar a evidenciação e a divulgação dos eventos ambientais, isto é, implantar a contabilidade ambiental. Nas demais empresas, não há intenção de realizar essa contabilização.

\subsection{Contabilidade ambiental sob a ótica dos gestores ambientais}

Com relação ao conhecimento dos gestores ambientais sobre a contabilidade ambiental, oito gestores declararam que já tomaram conhecimento desse novo ramo da contabilidade. Somente em duas empresas os gestores declararam não possuir informação sobre a contabilidade voltada para o meio ambiente.

Os gestores que estavam familiarizados com a contabilidade ambiental adquiriram conhecimento sobre ela por meio de participação em seminários e congressos e, também, através de jornais e revistas (Tabela 2). Verificou-se, ainda, que dois dos entrevistados argumentaram que tomaram conhecimento da contabilidade ambiental através de práticas na empresa, mas durante as entrevistas percebeu-se que nenhuma das empresas estudadas realizava a referida contabilidade. Diante do exposto, constatou-se que alguns gestores não possuíam conhecimento aprofundado do que seja a contabilidade ambiental, ou seja, da forma como as informações referentes ao meio ambiente devem ser evidenciadas nas demonstrações contábeis.

Constatou-se que metade dos entrevistados utilizava informações fornecidas pela contabilidade para tomar decisões referentes ao meio ambiente, pois, para efetuar investimento, é necessário verificar, no setor contábil,
Tabela 2-Fontes de informação dos gestores sobre a contabilidade ambiental.

Table 2 - Information sources of the managements about environmental accounting.

\begin{tabular}{lc}
\hline Comentários/Gestores ambientais & Respondentes \\
\hline Revistas/Jornais & 2 \\
Prática da empresa & 2 \\
Seminários/Congressos & 5 \\
Artigos & 4 \\
\hline
\end{tabular}

Fonte: Dados da pesquisa.

Source: Research data.

se há disponibilidade de recursos para serem aplicados em ações de natureza ambiental. Os demais entrevistados argumentaram que não as utilizavam, uma vez que as decisões eram tomadas pelos gestores e pela Direção da empresa em reuniões específicas.

Os cinco gestores que utilizavam as informações geradas pela contabilidade responderam que as usavam para avaliar projetos da empresa; desses, três também avaliaram os resultados da organização, e apenas um gestor utilizou informações contábeis para decidir sobre a obtenção de financiamentos. Constatou-se, nessa questão, a importância da informação contábil, pois, nas empresas, principalmente naquelas de grande porte, não se aprovava um projeto que requeria alto investimento, sem verificar a sua viabilidade econômicofinanceira.

Observou-se que $80 \%$ dos gestores ambientais entrevistados não divulgavam as informações de natureza ambiental de forma destacada nas demonstrações contábeis. Porém, dois dos entrevistados argumentaram que essas informações são evidenciadas em contas específicas nas referidas demonstrações.

Verificou-se que seis empresas não aplicavam a contabilidade ambiental. Isso demonstra que a maioria das organizações ainda desconhece as vantagens que a utilização da contabilidade do meio ambiente pode trazer para seus negócios. Outros três gestores afirmaram que a contabilidade ambiental é praticada na empresa, mas, durante a entrevista, percebeu-se que, na realidade, não se faz a contabilidade ambiental e, sim, que algumas empresas realizavam controle dos custos ambientais por meio do centro de custo. Esses resultados contrastam com as respostas dos contadores, que afirmaram, em sua totalidade, que não se realizava a contabilidade ambiental nas empresas em estudo. 
Ao solicitar que os entrevistados discorressem sobre os principais motivos da inexistência da contabilidade ambiental, verificou-se que essa não era realizada nas empresas estudadas devido à falta de conhecimento sobre o tema. Esse resultado evidencia a necessidade do desenvolvimento de estudos sobre o referido assunto e de sua divulgação para os profissionais da área contábil-administrativa. Os entrevistados também mencionaram a não obrigatoriedade de aplicação da contabilidade ambiental. De acordo com os relatos, isso se deveu ao fato de a atividade da empresa não implicar grande impacto sobre o meio ambiente.

As questões e os resultados das ações ambientais são contabilizados em três empresas estudadas da mesma forma que suas demais ações; somente em duas empresas houve modificações nos instrumentos contábeis, incorporando contas destinadas à contabilização desses eventos.

Para verificar como os gestores tomavam as decisões relacionadas ao meio ambiente, indagou-se sobre as fontes de informações utilizadas. Observou-se que, em três empresas, os gestores tomavam as decisões baseadas em Sistema de Contabilidade Tradicional. Isso comprova a resposta anterior, na qual afirmaram tratar as questões ambientais da mesma forma que as outras ações da sua área na empresa.

Em apenas uma empresa, o gestor relatou que utilizava instrumento próprio para tomar decisões, consistindo em um Relatório de Custo da Qualidade e Meio Ambiente. O relatório era constituído por custos negativos e custos positivos. Os custos negativos são aqueles referentes à recuperação de áreas afetadas pelas atividades do processo produtivo, enquanto os custos positivos estão relacionados aos investimentos realizados pela empresa, para prevenção de impacto ambiental, com o intuito de minimizar os custos negativos.

Buscou-se verificar se os gestores pretendem incorporar a contabilidade ambiental na contabilidade da empresa. Três entrevistados declararam que sim, argumentando que o fato de responderem ao questionário para esta pesquisa possibilitou-lhes adquirir um pouco de conhecimento sobre esse novo ramo da contabilidade. O gestor que não pretendia realizar a contabilidade ambiental disse que a empresa era familiar e quem tomava as decisões eram proprietários.
Nota-se que, por ser a contabilidade ambiental ainda assunto recente, os entrevistados não tinham conhecimento aprofundado sobre o tema, isto é, não possuíam noções claras sobre a sua principal finalidade. Isso pode ser a causa da não incorporação das informações ambientais nos registros contábeis das empresas com a sua devida evidenciação.

\section{CONCLUSÃO}

Esta pesquisa teve como finalidade fazer uma análise da contribuição das informações contábeis para a gestão ambiental, bem como a utilização específica da contabilidade ambiental no gerenciamento dos problemas ambientais. Concluiu-se que as empresas estudadas não faziam uso da contabilidade ambiental. Tratavam as questões e os resultados das ações ambientais de forma análoga às ações tradicionais da empresa, não fazendo, portanto, separação dos custos e despesas referentes ao meio ambiente. As decisões relacionadas ao meio ambiente, como a avaliação de projetos e resultados da empresa, eram tomadas com base em informações fornecidas pela contabilidade tradicional.

Quanto à evidenciação das informações de natureza ambiental de forma destacada nas demonstrações contábeis, verificou-se que, em nenhuma das empresas estudadas, essas informações eram apresentadas separadamente nos relatórios contábeis. Além disso, foi constatado que essas empresas divulgavam os eventos econômicos ou fatos contábeis relativos às ações ambientais realizadas por elas, principalmente em Relatórios Administrativos e no Balanço Social.

Embora alguns entrevistados tenham afirmado que conheciam a contabilidade voltada para o meio ambiente, verificou-se que desconheciam ainda os benefícios da sua utilização. Nesse sentido, alguns entrevistados relataram que aplicavam a referida contabilidade nas empresas, mas foi possível verificar que, na realidade, a contabilidade ambiental não foi implantada, permanecendo apenas a contabilidade tradicional, pois não se encontrou nas empresas pesquisadas qualquer demonstração contábil, evidenciando informações relacionadas ao meio ambiente.

Assim, ao profissional de contabilidade, a contabilidade ambiental se apresenta como grande desafio, pois, além de possuir os conhecimentos da contabilidade tradicional, terá que se preparar para atuar nesse novo ramo contábil, ou seja, será necessário conhecer as ações ambientais realizadas pelas empresas para que possa evidenciá-las de forma transparente e objetiva.

Revista Árvore, Viçosa-MG, v.34, n.6, p.1119-1128, 2010 


\section{REFERÊNCIAS}

BERGAMINI JUNIOR, S. Custos emergentes na contabilidade ambiental. Balanço Social: Responsabilidade Social e Ambiental, v.3, n.9, p.3-11, 2000.

CARDOSO, A. C. O valor da contabilidade ambiental agregado ao planejamento estratégico organizacional. Pensar Contábil, v.8, n.33, p.26-32, 2006.

COSENZA, J. P.; KROETZ, C. E. S. Formas de apresentação da informação social e ambiental. Pensar Contábil, v.8, n.33, p.5-19, 2006.

CONSELHO FEDERAL DE CONTABILIDADE CFC. Resolução CFC n. 1.003/04. Aprova a NBC T 15 - Informações de Natureza Social e Ambiental. Brasília: 2004. Disponível em: <http:// cfcspw.cfc.org.br/resolucoes_cfc/Res_1003.doc>. Acesso em: 15/11/2004.

EPELBAUM, M. A influência da gestão ambiental na competitividade e no sucesso empresarial. 2004. 190f. Dissertação (Mestrado) - Universidade de São Paulo, São Paulo, 2004.

FERREIRA, A. C. S. Uma contribuição para a gestão econômica do meio ambiente: um enfoque de sistema de informações. 1998. 162f.. Tese (Doutorado) - Universidade de São Paulo, São Paulo, 1998.

FERREIRA, A. C. S. Contabilidade ambiental: Uma informação para o desenvolvimento sustentável. São Paulo: Atlas, 2003. 144p.

KRAEMER, M. E. P. Contabilidade ambiental como sistema de informações. Balanço Social: Responsabilidade Social e Ambiental, v.3, n.9, p.19-26, 2000.

MARTINS, E.; DE LUCA, M. M. Ecologia via contabilidade. Revista Brasileira de Contabilidade, v.29, n.86, p.20-29, 1994.

NARDELLI, A. M. B.; GRIFFITH, J. J. Introdução ao sistema de gestão ambiental. Viçosa, MG: Universidade Federal de Viçosa, 2000. 60p. (Apostila de Curso).
NOSSA, V. Disclosure ambiental: uma análise do conteúdo dos relatórios ambientais de empresas do setor de papel e celulose em nível internacional. 2002. 246f. Tese (Doutorado) - Universidade de São Paulo, São Paulo, 2002.

OLIVEIRA FILHO, M. L. A auditoria ambiental como ferramenta de apoio para o desempenho empresarial e a preservação do meio ambiente: uma abordagem contábil e gerencial em indústrias químicas. 2002.182f. Dissertação (Mestrado) Universidade de São Paulo, São Paulo, 2002.

RIBEIRO, M. S. Custeio das atividades de natureza ambiental. 1998. 242f. Tese (Doutorado) - Universidade de São Paulo, São Paulo, 1998.

RIBEIRO, M. S.; GRATÃO, A. D. Custos ambientais - o caso das empresas distribuidoras de combustíveis. In: CONGRESSO BRASILEIRO DE CUSTOS, 7., 2000, Recife. Anais... Recife: 2000. Paginas

SOARES, E.; ANDRADE, M. A evidenciação dos passivos ambientais. Balanço Social: Responsabilidade Social e Ambiental, v.3, n. 9, p.49-53, 2000.

\section{UNITED STATED ENVIRONMENTAL} PROTECTION AGENCY - USEPA. An introduction to environmental accounting as a business management tool: key concepts and terms. 1995. Disponível em: <http://www.epa.gov/oppt/acctg/ pubs/busmgt.pdf>. Acesso em: 10/06/2004.

\section{UNITED NATIONS CONFERENCE ON TRADE AND DEVELOPMENT - UNCTAD.}

\section{Environmental Financial Accounting} and Reporting at the Corporate Level. 1998. Disponível em: < http://www.unctad.org/en/ docs/isa15d2.pdf $>$. Acesso em: 20/06/2004.

VERGARA, S. C. Projetos e relatórios de pesquisa em administração. São Paulo: Atlas, 2005. 96p.

VIANA, E. C. et al. Análise técnico-jurídica do licenciamento ambiental e sua interface com a certificação ambiental. Revista Árvore, v.27, n.4, p.587-595, 2003. 